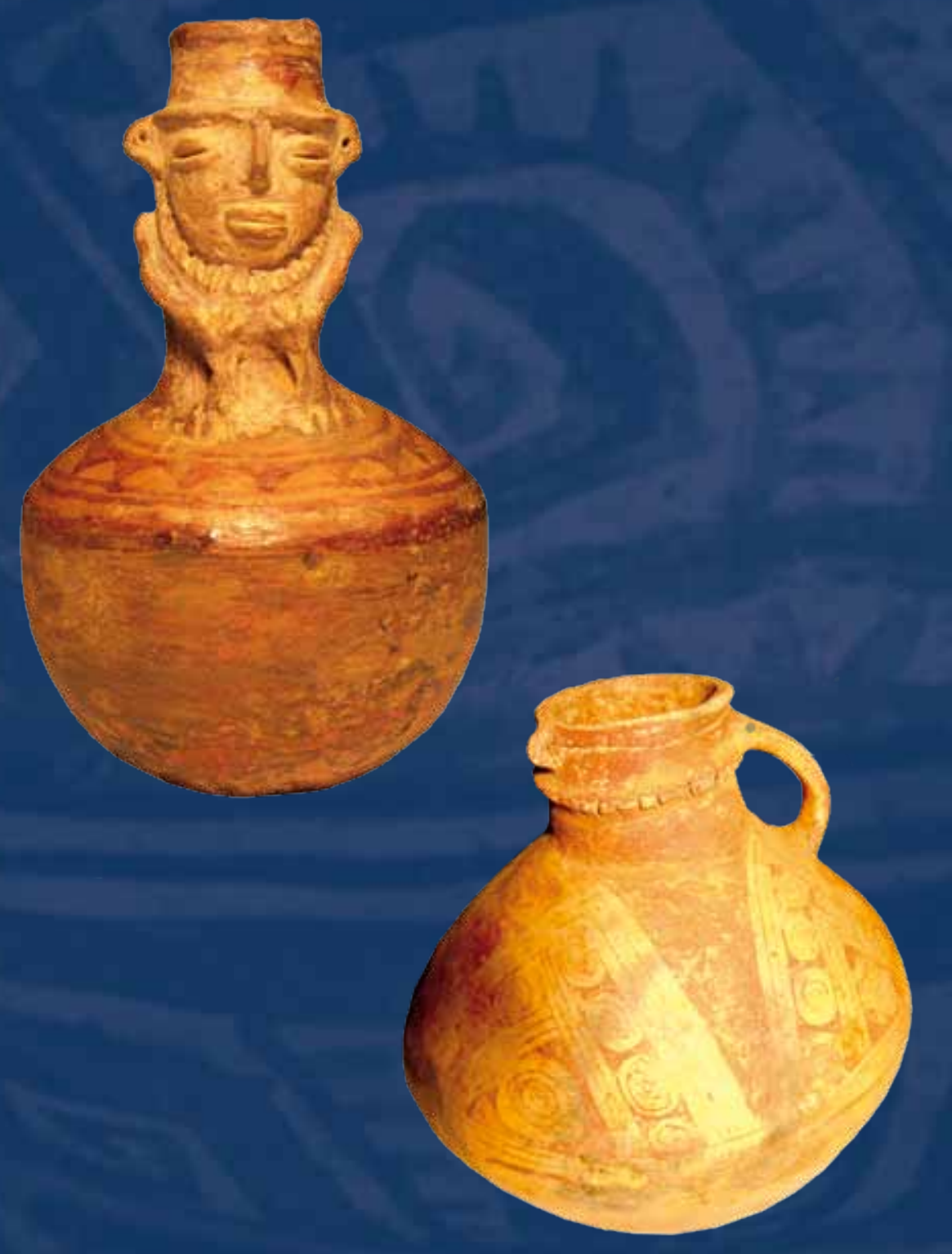

INVESTIGACIÓN 


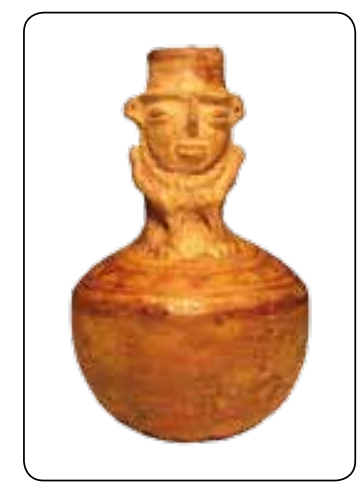

No. de Registro: UST.C.1335

Cronología: Siglo X-XVI D.C.

Denominación: Múcura antropomorfa

Diseño: En el hombro lleva una banda compuesta por motivos triangulares unidos, la cual se vuelve a repertir en el tocado del individuo. En el asa lleva líneas horizontales. El personaje presenta pintura en la cara y parte del cuerpo. La forma del recipiente es de cuerpo subglobular, cuello cilíndrico, borde recto y labio plano. La base de la pieza es convexa y posee un asa de sección plana maciza vertical. Tiene modelado en el cuello un personaje sentado con collar y posiblemente tocado.

Tipo cerámico indefinido Muisca-Guane. El individuo está sentado con las manos al frente sobre las rodillas. Los rasgos individuales se lograron por impresión, modelado, aplicación y otros.

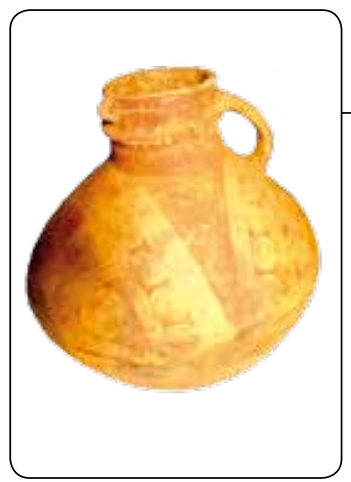

No. de Registro: UST.C. 1050

Cronología: Siglo X-XVI D.C.

Denominación: Cántaro

Diseño: Total en cuello, borde y labio. En el hombro tiene triángulos concéntricos que llevan dentro círculos concéntricos algunos de ellos con T. También líneas paralelas horizontales. Pintura en el asa. Su forma corresponde a un cuerpo subglobular, hombro redondeado, cuello cilíndrico, borde evertido, labio redondeado y base convexa. Lleva asa vertical de sección plana. En el cuello tiene una banda aplicada con impresiones (muescas) y en el borde falsas agarraderas. Tipo cerámico Curití Poroso. Tiene manchas de cocción. 


\title{
ANÁLISIS DE LAS PRINCIPALES INICIATIVAS SUPRANACIONALES EN LA LUCHA CONTRA LA CORRUPCIÓN
}

\author{
Carmen Demelsa Benito Sánchez \\ Candidata a Doctor en Aspectos jurídicos y económicos de la corrupción, Diploma de Estudios \\ Avanzados, Universidad de Salamanca (España); Licenciada en Derecho, Universidad de \\ Salamanca, (España); Becaria FPU-MEC (España). \\ E: mail: demelsa@usal.es
}

\begin{abstract}
Resumen
El objetivo del presente artículo es analizar las iniciativas internacionales y regionales más relevantes en la lucha contra la corrupción desde la Convención Interamericana contra la Corrupción de 1996 hasta la Convención de Naciones Unidas contra la Corrupción del año 2003. El trabajo se centra en el estudio de las medidas represivas de los comportamientos corruptos, presta especial consideración a la necesidad de tipificar como delito la corrupción de funcionarios públicos ya sean nacionales, extranjeros o de organizaciones internacionales, así como la corrupción entre privados.
\end{abstract}

\section{Palabras clave}

Convención Interamericana contra la Corrupción, Convención de Naciones Unidas contra la Corrupción, Comportamientos corruptos, Funcionarios públicos, organizaciones internacionales.

\begin{abstract}
Abstrac
The objective of the present paper is to analyze the more important international and regional initiatives in the fight against corruption, from the Inter-American Convention against Corruption of year 1996 to the United Nations Convention against Corruption of year 2003. The article concentrates on the study of the repressive measures of corruptive behaviors, taking the necessity to establish as criminal offence the corruption of national and foreign officials and the corruption of international organizations officials, as well as the private corruption, into special consideration.
\end{abstract}

\section{Key Words}

Inter-American Convention against Corruption, United Nations Convention against Corruption, Corruptive behaviors, Officials, International organizations. 


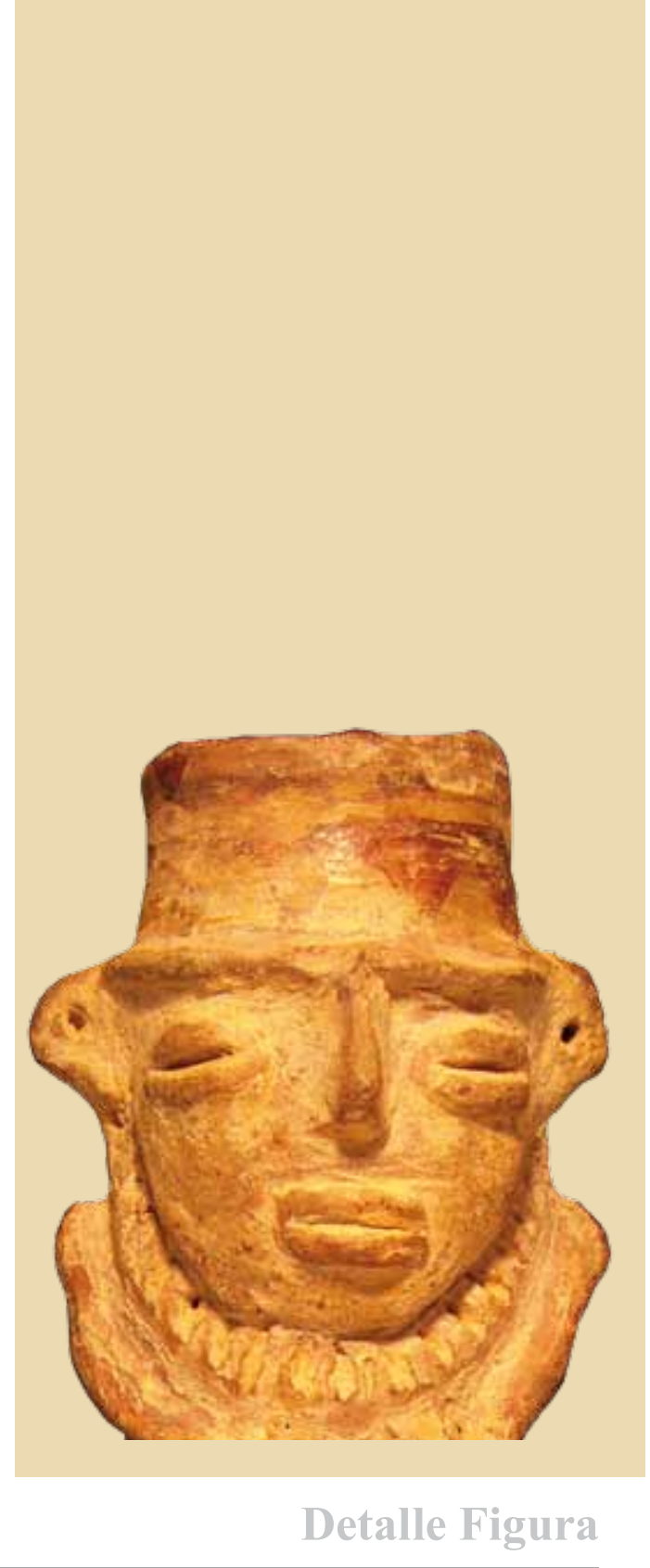

Múcura antropomorfa 


\section{ANÁLISIS DE LAS PRINCIPALES INICIATIVAS SUPRANACIONALES EN LA LUCHA CONTRA LA CORRUPCIÓN*}

Carmen Demelsa Benito Sánchez

\section{INTRODUCCIÓN}

Sin ser un fenómeno nuevo en la historia de la humanidad ${ }^{1}$, la corrupción ha adquirido una notable dimensión en las dos últimas décadas. Pensemos en los escándalos protagonizados en los noventa por Alberto Fujimori en Perú, Collor de Mello en Brasil, Mobutu en El Congo o Suharto en Indonesia, así como el entramado destapado por la operación mani pulite en Italia. Es tal la magnitud que ha cobrado el fenómeno en los últimos años que para referirse a él se ha empleado terminología como la gran corrupción ${ }^{2}$ o corrupción planetaria (Nieto, 1997, 51).

* $\quad$ El presente artículo de investigación se inscribe en el marco del Proyecto I+D "El tratamiento jurídico-penal del blanqueo de capitales a la luz de las iniciativas internacionales más recientes contra la corrupción", financiado por el Ministerio de Educación y Ciencia (España) (Referencia SEJ2006-13439).

1 Su origen se considera tan antiguo que hay quien califica la corrupción de "consustancial al ser humano". Vercher Noguera, Antonio: "La corrupción urbanística. Una nueva expresión delictiva", en Claves de Razón Práctica, No. 139, enero-febrero, 2004, p. 26. Por citar un ejemplo de su carácter inmemorial, ya se discutía sobre corrupción en un libro de hace 2000 años, el Arthashastra, escrito por Kautilya, un ministro de un reino indio. La referencia procede de Tanzi, Vito: "Corruption around the World: causes, consequences, scope and cures", en Abend, George T. Y Gupta, Sanjeev (ed.): Governance, Corruption and eco nomic performance, International Monetary Fund, Washington D.C., 2002, p. 19.

2 Moody-Stuart, George: La gran corrupción. Versión castellana: M. Margaret Casagualda. Siddharta Mehta Ediciones, Madrid, 1994. 
Precisamente, si algo caracteriza a la corrupción en nuestros días es su dimensión mundial, internacional, "planetaria". A ello ha contribuido sin lugar a dudas el imparable proceso globalizador que vive la sociedad actual ya que si las fronteras físicas e incluso políticas entre los Estados desaparecen por efecto de la globalización, desaparecen también para los delincuentes, entre ellos, los corruptos. Como afirma el Preámbulo de la Convención de Naciones Unidas contra la Corrupción del año 2003: "la corrupción ha dejado de ser un problema local para convertirse en un fenómeno transnacional que afecta a todas las sociedades y economías".

En este contexto, las iniciativas puramente nacionales contra la corrupción se muestran insuficientes, por lo que será necesaria la colaboración y la cooperación entre los Estados para acabar con este mal que azota a la sociedad actual ${ }^{3}$.

Sin embargo, mientras que la comunidad internacional se ha preocupado por otros temas - no menos importantes que la corrupción, como el tráfico de drogas - , desde hace varias décadas ${ }^{4}$, se tendrá que esperar hasta mediados de los años noventa para ver nacer las primeras iniciativas internacionales vinculantes en la lucha contra la corrupción. A continuación se procederá al análisis de las más relevantes.

\section{LA CONVENCIÓN INTERAMERICANA CONTRA LA CORRUPCIÓN}

Elaborada bajo los auspicios de la Organización de Estados Americanos, constituye, el primer documento internacional vinculante dedicado íntegramente a la lucha contra la corrupción. El documento refleja el compromiso asumido por los países latinoamericanos de un lado, que ven satisfechos sus intereses en materia de asistencia recíproca y extradición, y los EE.UU de otra, que ven cumplida su vieja reivindicación en cuanto a la penalización del cohecho activo en el comercio transnacional ${ }^{5}$.

Los orígenes de esta convención se encuentran en la Cumbre de Presidentes de las Américas, celebrada en Miami en diciembre de 1994, en la cual, el gobierno de Venezuela presentó un proyecto de convención que sería la base sobre la que

3 Carrera, F. Jesús: "La persecución penal de la corrupción en la Unión Europea", en VV.AA.: Cooperación jurídica internacional, Colección Escuela Diplomática. BOE, Madrid, 2001, p. 208.

4 Convención Única sobre estupefacientes, firmada en Nueva York el 30 de marzo de 1961, enmendada por el Protocolo que modifica la Convención Única sobre estupefacientes de 1961, hecho en Nueva York el 8 de agosto de 1975; Convenio sobre sustancias psicotrópicas, hecho en el Viena 1 de febrero de 1971; Convención de Naciones Unidas contra el tráfico ilícito de estupefacientes y sustancias psicotrópicas, celebrada en Viena el 19 de diciembre de 1988.

5 PIETH, Mark: "International Efforts to Combat Corruption", en ALVAZZI DEL FRATE, Anna y PASQUA, Giovanni (eds.): Responding to the Challenges of Corruption, UNICRI - ISPAC CNPDS, Roma - Milán, 2000, p. 27. Estados Unidos castiga el soborno activo en el comercio internacional desde 1977 a través de su Foreign Corrupt Practices Act. 
trabajaría el Grupo de Trabajo de la Asamblea General de la OEA, "Probidad y Ética Cívica", para la elaboración del texto definitivo que se aprobaría en Caracas el 29 de marzo de $1996^{6}$.

La Convención contiene medidas tanto de carácter preventivo como de carácter represivo. Y dentro de estas últimas se sitúan aquellas que instan a los Estados Parte a tipificar determinadas conductas como delito y las referidas a la asistencia y cooperación entre los Estados.

Las medidas preventivas se recogen en el artículo 3 del documento. Este precepto tiene un carácter menos imperativo que el resto de la Convención, como lo demuestra la fórmula en él utilizada: "los Estados Partes convienen en considerar la aplicabilidad de medidas..." . Entre las medidas preventivas que se señalan destacan la adopción de normas de conducta para el correcto desempeño de la función pública (Art. 3.1), el establecimiento de sistemas para la declaración de ingresos por parte de las personas que desempeñan funciones públicas (Art. 3.4), para la contratación de funcionarios públicos y para la adquisición de bienes y servicios por parte del Estado que aseguren la publicidad, equidad y eficiencia de tales sistemas (Art. 3.5), la adopción de sistemas para proteger a funcionarios públicos y ciudadanos particulares que denuncien de buena fe actos de corrupción (Art. 3.8), la adopción de mecanismos para asegurar que las sociedades mercantiles y otros tipos de asociaciones mantengan registros que reflejen con exactitud y razonable detalle la adquisición y enajenación de activos, y que establezcan suficientes controles contables internos (Art. 3.10) y otros.

Entre las medidas represivas relativas a la tipificación de delitos, están, por una parte, aquellas con mayor fuerza obligatoria, que obligan a criminalizar las conductas descritas sin condiciones. Aquí se sitúan los Art. 6 y 7. El Art. 6 describe lo que la Convención entiende por actos de corrupción, estos son, el cohecho clásico tanto pasivo (Art. 6.1.a) como activo (Art. 6.1.b), y otras figuras que se corresponderían con lo que suele denominarse negociaciones incompatibles con la función pública o incumplimiento de los deberes de la función pública ${ }^{8}$ (Art. 6.1.c). También exige el mismo precepto la tipificación del blanqueo y el encubrimiento de los bienes provenientes de los delitos enumerados, así como de las diferentes formas de participación y la tentativa. El Art. 7 obliga a los Estados parte a adoptar las medidas necesarias para tipificar como delito los actos de corrupción descritos en el artículo anterior y para facilitar la cooperación entre ellos.

Por otra parte, con menor fuerza obligatoria que los dos artículos anteriores se sitúan los Art. 8 y 9, que incluyen ambos una cláusula de salvaguarda en virtud

$6 \quad$ La Convención entró en vigor el 6 de marzo de 1997.

7 La opción por esta fórmula resultó de la especificidad de las medidas previstas en este Art. 3, lo cual implica que los Estados Parte las deban adoptar de acuerdo a sus propias costumbres e instituciones Manfroni, Carlos A. y Werksman, Richard: La Convención Interamericana contra la corrupción. Anotada y comentada, Abeledo-Perrot, Buenos Aires, 1997, p. 56.

8 Manfroni, Carlos A. y Werksman, Richard: La Convención Interamericana ..., Op. cit., p. 96. 
de la cual los Estados tendrán en consideración su Constitución y los principios fundamentales de su ordenamiento jurídico a la hora de dar cumplimiento a lo exigido por ambos preceptos. En concreto, el Art. 8 obliga a los Estados Parte a prohibir y sancionar, si bien no dice penalmente, luego pueden utilizarse otras ramas del ordenamiento jurídico, el soborno otorgado a funcionarios públicos de otros Estados en el transcurso del comercio transnacional, configurándose así como el primer precepto en un documento obligatorio supranacional que insta a los Estados Parte a sancionar el soborno de funcionarios $\mathrm{p}$ úblicos extranjeros.

Con el mismo nivel de obligatoriedad que el Art. 8, el Art. 9 insta a los Estados Parte a tipificar como delito el enriquecimiento ilícito, esto es, "el incremento del patrimonio de un funcionario público con significativo exceso respecto de sus ingresos legítimos durante el ejercicio de sus funciones y que no pueda ser razonablemente justificado por él".

Con un grado de compromiso menor que el de los Art. 6, 7, 8 y 9 se sitúa el Art. 11, en virtud del cual los Estados Parte "estiman conveniente y se obligan a considerar la tipificación en sus legislaciones" de las conductas en él enumeradas, esto es, el uso indebido por parte de funcionarios públicos o personas que ejerzan funciones públicas de información reservada o privilegiada, el uso o aprovechamiento indebido por parte de un funcionario público o persona que ejerza funciones públicas de bienes del Estado, cualquier comportamiento de un particular dirigido a la adopción por parte de la autoridad pública de una decisión en virtud de la cual obtenga ilícitamente un beneficio, así como la desviación de su objeto que hagan los funcionarios públicos de bienes, dinero o valores que pertenezcan al Estado, a un organismo descentralizado o a un particular, que los hubieran percibido por razón de su cargo, en administración, depósito o por otra causa.

Como se mencionó al inicio del presente apartado, existe otro grupo de medidas dentro de las represivas destinado a articular la cooperación de los Estados parte en la lucha contra la corrupción. Así, en el Art. 13 se regula la extradición. Los delitos que los Estados hayan tipificado de conformidad con la Convención se considerarán incluidos entre los delitos que den lugar a la extradición en todo tratado de extradición vigente entre ellos, y además, se comprometen a incluirlos en tratados que se celebren en el futuro. Cuando un Estado Parte, que supedite la extradición a la existencia de un tratado, reciba una solicitud de otro Estado Parte, con el que no le vincula tratado alguno, podrá considerar la Convención como base jurídica para la extradición respecto de los delitos tipificados conforme a ella. Cuando la extradición no se supedite a la existencia de un tratado, se deberá aplicar la Convención respecto de esos delitos.

En virtud del Art. 14 las partes se obligan a prestarse asistencia recíproca para la investigación y enjuiciamiento de los actos de corrupción descritos en la Convención. Dicha asistencia no se limita a las solicitudes emanadas de órganos judiciales, pues el precepto se refiere a "autoridades que tengan facultades para la investigación o juzgamiento", luego se extiende a otras instituciones como la policía y el Ministerio 
Fiscal. El segundo inciso del precepto obliga a los Estados parte a prestarse la más amplia cooperación técnica en la lucha contra la corrupción.

Es importante señalar que los Estados Parte deberán brindarse asistencia y cooperación en relación con los delitos descritos en los Art. 8, 9, y 11 de la Convención, incluso aunque no hayan sido tipificados como tales en sus legislaciones internas.

Si importante es la persecución y enjuiciamiento de los delincuentes corruptos, tanto o más lo es la persecución de los bienes obtenidos por éstos con la realización de actos de corrupción. El dinero que sustraen los corruptos impide que aquéllos que lo necesitan reciban alimentos, educación o sanidad. Por ello, ir tras ese dinero, recuperarlo y devolvérselo a los pueblos a los que fue sustraído constituye uno de los principales objetivos que debe perseguir la comunidad internacional en su lucha contra la corrupción. Un paso adelante en esta dirección es el dado por la Convención Interamericana contra la Corrupción a través de su Art. 15, el cual obliga a los Estados Parte a prestarse la más amplia asistencia posible en la identificación, rastreo, inmovilización, confiscación y decomiso de bienes obtenidos o derivados de la comisión de los delitos tipificados de conformidad con la Convención, de los bienes utilizados en dicha comisión o del producto de dichos bienes.

Por último, el Art. 16 impide a los Estados Parte alegar el secreto bancario para negarse a brindar la asistencia solicitada por un Estado Parte requirente.

\section{INICIATIVAS PROCEDENTES DE LA ORGANIZACIÓN PARA LA COOPERACIÓN Y EL DESARROLLO ECONÓMICO. ESPECIAL REFERENCIA AL CONVENIO DE LUCHA CONTRA LA CORRUPCIÓN DE AGENTES PÚBLICOS EXTRANJEROS EN LAS TRANSACCIONES COMERCIALES INTERNACIONALES}

\section{Primeras actuaciones de la OCDE contra la corrupción transnacional}

Los primeros trabajos de la OCDE en materia de corrupción se remontan a 1976, fecha en que la organización adopta una suerte de código deontológico para las empresas multinacionales denominado Líneas Directrices de la OCDE para empresas multinacionales. EE.UU. fue el impulsor de esta iniciativa, motivado por los recién destapados escándalos sobre corrupción que impregnaron en aquel entonces la vida política y empresarial del país (Fabián, 2003, 64). El apartado VI de las citadas Líneas se dedica a la lucha contra la corrupción, recomendando a las empresas no entregar pagos ilícitos o ventajas indebidas para obtener o conservar un contrato $u$ otra ventaja ilegítima. Sin embargo, hasta que las tensiones políticas y económicas de la Guerra Fría no fueron superadas, no se retomaron los trabajos contra la corrupción en el seno de la OCDE. De este modo, en 1989 se creó un Grupo de Trabajo, otra 
vez a instancia de EE.UU., único país que, ya desde la Foreign Corrupt Practices Act de 1977 sancionaba a sus empresas por pagar sobornos a funcionarios públicos extranjeros en el transcurso de una operación comercial internacional ${ }^{9}$. El objetivo estaba claro: luchar contra la corrupción en el comercio internacional y diseñar unas condiciones de competencia iguales para todas las empresas participantes en él ${ }^{10}$. Los trabajos culminaron con la adopción por parte del Consejo de la Recomendación para combatir el cohecho en las transacciones comerciales internacionales, de 27 de mayo de 1994.

Se trataba de un texto sin carácter vinculante pero, a partir del cual, los Estados firmantes comenzaron a introducir modificaciones en sus Ordenamientos internos en aras a lograr el objetivo fijado de evitar pagos ilícitos en el comercio internacional ${ }^{11}$. Además, la Recomendación incluía un mecanismo de seguimiento, lo que demostraba un mayor compromiso por parte de los Estados de la OCDE de cumplir con ella ${ }^{12}$.

La Recomendación de 1994 contenía un compromiso de revisión, fruto del cual nació la Recomendación Revisada sobre el combate al cohecho en las transacciones comerciales internacionales, adoptada por el Consejo del 23 de mayo de 1997. En la misma se recomienda a los Estados firmantes que tipifiquen penalmente el cohecho de servidores públicos extranjeros, a la vez que se decide iniciar negociaciones para la elaboración de un convenio internacional sobre dicha materia. También se exhorta a los Estados firmantes a que eliminen la deducción fiscal de los sobornos a servidores públicos extranjeros, dando cumplimiento así a la Recomendación sobre la posibilidad de deducir el cohecho a funcionarios públicos extranjeros adoptada por el Consejo el 11 de abril de 1996. Igualmente, se recomienda a los Estados que adopten medidas en el ámbito de la contabilidad, auditoría externa y control interno de las empresas para prevenir el soborno transnacional. Además, deberían suspender de la competencia por contratos públicos a las empresas que hubieran realizado pagos ilícitos a funcionarios públicos extranjeros. Del mismo modo, se les recomienda adoptar medidas sobre cooperación internacional para la investigación de los supuestos de cohecho. La Recomendación Revisada prevé un mecanismo de seguimiento para supervisar y fomentar la completa puesta en marcha de la misma

$9 \quad$ Cerezo, A. (2001). "La adaptación del sistema jurídico-penal español a las propuestas internacionales sobre corrupción administrativa", en Actualidad Penal, no 21, XXI, p. 454; Madrid, M. (1998). "Acciones internacionales en la lucha contra la corrupción” Derecho de los negocios, Año No 9, No 91, 1998 p. 6; Sacerdoti, G. (2000). “'Sobornar o no sobornar? OCDE (Ed.): Las reglas del juego cambiaron: La lucha contra el soborno y la corrupción, OCDE, México, 2000, p. 36.

10 OCDE (Ed.): Las reglas del juego cambiaron..., Op. cit., p. 3

11 Cebada, A. (2002). "La participación española en las acciones internacionales contra la corrupción", en Derecho de los Negocios, año 13 N 144 , septiembre, p. 25; Cerezo, A. "La adaptación...", Op. cit., p. 454; Madrid, M. “Acciones internacionales...”, Op. cit., p. 6.

12 Cebada, A. "La participación española...", Op. cit., p.25; Madrid, M. "Acciones internacionales...", Op. cit., p. 6 
que incluye, por ejemplo, revisiones periódicas de las medidas tomadas por los países miembros y examen de temas específicos relacionados con el cohecho en las transacciones comerciales internacionales.

A la Recomendación Revisada se añadieron unos elementos comunes acordados (agreed common elements) en materia de corrupción transnacional elaborados por el Grupo de Trabajo, que constituirían la base de una convención internacional sobre penalización del soborno a servidores públicos extranjeros, la cual debería estar abierta a la firma a finales de 1997. De este modo, el Grupo de Trabajo, transformado en Conferencia Negociadora, adoptó el 21 de noviembre de 1997 el Convenio de lucha contra la corrupción de agentes públicos extranjeros en las transacciones comerciales internacionales, que se abriría a la firma en París el 17 de diciembre de $1997^{13}$.

Este Convenio marca un antes y un después en la lucha contra la corrupción transnacional. Un tema al que pocos Estados habían prestado atención, aun cuando todos castigaban el soborno a funcionarios públicos nacionales. Un tema que no tenía por qué ser aceptado como algo inherente a la globalización económica. Desde ese momento ya no sólo existen razones éticas para negarse a pagar sobornos a servidores públicos de otros Estados, ahora las empresa cuentan también con un marco legal en el que apoyarse.

\section{Análisis del Convenio de lucha contra la corrupción de agentes públicos extranjeros en las transacciones comerciales internacionales}

La adopción de un texto con carácter vinculante, como el que ahora nos ocupa, por parte de la Conferencia Negociadora no fue tarea fácil, de ahí que algunas cuestiones referentes al Convenio se explicaran en unos Comentarios, un documento separado del mismo adoptado por la Conferencia Negociadora a la vez que el Convenio. $\mathrm{Su}$ naturaleza jurídica es controvertida, pues no forman parte del Convenio, no tienen carácter vinculante y no son objeto de firma o ratificación por los Estados que suscriban el Convenio. En opinión de SACERDOTI, ofrecen un "elemento significativo del contexto" en el cual se elaboró el Convenio ${ }^{14}$ y constituyen una guía para la interpretación de la Convención, si bien no se trataría de una interpretación concluyente y auténtica ${ }^{15}$.

13 El Convenio entró en vigor el 15 de febrero de 1999.

14 Sacerdoti, G. “Sobornar o no sobornar?, Op. cit., p. 41. “Contexto” al que se refiere el Art. 31 de la Convención de Viena sobre el Derecho de los Tratados de 23 de mayo de 1969, en el cual se señala que "el contexto comprenderá, además del texto, incluidos su preámbulo y anexos: a) todo acuerdo que se refiera al tratado y haya sido concertado entre todas las partes con motivo de la celebración del tratado y b) todo instrumento formulado por una o más partes con motivo de la celebración del tratado y aceptado por las demás como instrumento referente al tratado".

15 Sacerdoti, G. Op. cit., p. 41. 
Por otra parte, la divergencias existentes entre los Ordenamientos jurídicos de los diferentes Estados Parte dificultaban la adopción de un acuerdo vinculante que exigiera la incorporación a las legislaciones internas de disposiciones idénticas. Por ello, la Conferencia Negociadora elaboró el criterio de la equivalencia funcional, que fue incorporado al Convenio en su preámbulo y al que los Comentarios le dedican su apartado 2. En virtud de este criterio, lo importante es que las Partes obtengan unos resultados equivalentes a pesar de que para ello sigan caminos diferentes ${ }^{16}$.

El Convenio prevé la tipificación, exclusivamente, del cohecho activo (Art. 1.1), es decir, el delito cometido por la persona que ofrece o promete un soborno a un funcionario público, no ocupándose del cohecho pasivo, esto es, el delito cometido por el funcionario público que solicita o acepta el soborno. Tampoco se ocupa el Convenio de la corrupción entre privados. La conducta típica que se recoge consiste en ofrecer, prometer o conceder deliberadamente cualquier beneficio indebido pecuniario o de otra clase a un agente público extranjero, directamente o mediante intermediarios. No se consideran beneficios indebidos y, por tanto, no habrá delito, aquellos que están permitidos o exigidos por las leyes escritas o reglamentos del país del agente público extranjero y por la jurisprudencia (Comentario 8). Por el contrario, sí se considerará delito la entrega de pagos indebidos aunque esté permitida por las costumbres locales o sea tolerada por las autoridades locales, e incluso la entrega en supuestos estados de necesidad. Según el Convenio OCDE, no constituyen delito los denominados "pagos de facilitación" (Comentario 9), es decir, aquellos que se realizan para agilizar trámites administrativos, siempre que consistan en pequeñas cantidades de dinero.

El texto del Convenio ofrece una definición autónoma de agente público extranjero, completada en los Comentarios 12 a 18, que no tiene por qué coincidir con lo que hasta el momento se entendiera en los Ordenamientos internos de los Estados Parte por funcionario público. Así, quedan incluidos en la noción desarrollada por el Convenio, cualquier persona que ostente un cargo legislativo, administrativo o judicial, tanto por nombramiento como por elección; cualquier persona que ejerza una función pública que le haya sido delegada por el Estado, cualquier organismo público, cualquier empresa sobre la cual el gobierno ejerza directa o indirectamente una influencia dominante, por ejemplo, porque ostente la mayoría del capital social; por último, se incluyen también funcionarios o agentes de organizaciones internacionales públicas. Se trata, pues, de un concepto amplio en el que incluso $y$, por primera vez, en un texto internacional, se hace mención a funcionarios de organizaciones internacionales, sin embargo, no se consideran incluidos en dicho

16 Pieth, Mark: "Die Strafbarkeit der activen Bestechung ausländischer Beamter”, en: Pieth, Mark y Eigen, Peter (Hrsg): Korruption im internationalen Geschäftsverkehr. Bestandsaufnahmen, Bekämpfung, Prävention, Ed. Luchternahd, Frankfurt am Main, 1998, p. 345. Sacerdoti, Giorgio: op. cit., p. 39. 
concepto los partidos políticos o candidatos para un cargo público, que sí se incluían en la Foreign Corrupt Practices Act ${ }^{17}$.

El beneficio indebido debe entregarse con una finalidad concreta, esto es, que el agente actúe o se abstenga de actuar en relación con el ejercicio de funciones oficiales. Se incluye aquí todo supuesto de uso de la posición del agente público ya actúe dentro o fuera de su competencia (Art. 1.4.c y Comentario 18). Además de esta finalidad inmediata, se exige también una finalidad mediata: el soborno debe estar orientado a conseguir o conservar un contrato $\mathrm{u}$ otro beneficio irregular en la realización de actividades económicas internacionales.

Por su parte, el apartado 2 del Art. 1 exige también a los Estados Parte la tipificación de diferentes formas de autoría y participación en el delito así como la autorización de un acto de corrupción de agente público extranjero. Los ordenamientos jurídicos que penalicen la tentativa y la confabulación para corromper a agentes públicos nacionales deberán hacerlo extensible a la corrupción de agentes públicos extranjeros.

El Art. 2 del Convenio hace referencia a la responsabilidad de las personas jurídicas, si bien, no se exige a las Partes que reconozcan la responsabilidad penal de las personas jurídicas cuando en sus Ordenamientos jurídicos no se reconozca (Comentario 20).

El Convenio exige que las penas aplicables al delito de corrupción de agentes públicos extranjeros sean eficaces, proporcionadas y disuasorias, similares a las que se aplican para la corrupción de los propios funcionarios y que permitan una asistencia mutua efectiva y la extradición (Art. 3.1). Cuando un Estado no reconozca la responsabilidad penal de las personas jurídicas, establecerá sanciones no penales eficaces, proporcionadas y disuasorias (Art. 3.2). Además, las Partes regularán el embargo y confiscación del soborno y del producto de la corrupción o de bienes por valor equivalente (Art. 3.3)

El Convenio OCDE se asienta sobre el principio de territorialidad (Art. 4.1), que debe interpretarse en un sentido amplio, de modo tal que no exija una amplia conexión física con el acto de corrupción (Comentario 25). Cuando una parte reconozca el principio de personalidad activa, éste deberá aplicarse también respecto al delito de corrupción de agente público extranjero (Art. 4.2). No se trata de un precepto de carácter facultativo, es obligatorio, pero únicamente para los Estados que tengan reconocido ese principio en sus ordenamientos internos (Manfroni, 1998, 122). Esto no significa que allá donde no se persiga a sus nacionales por delitos cometidos en el extranjero, la conducta quede impune, sino simplemente que la jurisdicción por nacionalidad se establecerá de acuerdo a los principios y condiciones generales del

17 Que critica la no inclusión de partidos políticos y de sus candidatos, vid. Brademas, John y Heimann, Fritz: "Contra la corrupción internacional”, en Politica Exterior, Vol. XII, noviembre-diciembre 1998, no 66, p. 142; Rose-Ackerman, Susan: La corrupción y los gobiernos. Causas, consecuencias y reforma, Siglo Veintiuno de España Editores, Madrid, 2001 (traducción de Alfonso Colondrón Gómez), p. 255 
ordenamiento jurídico de cada parte (Comentario 26). El último apartado del Art. 4 exige a las Partes que revisen la base de su actual jurisdicción si no es eficaz para luchar contra la corrupción de agentes públicos extranjeros y que tomen medidas para subsanarlo.

La relación existente entre el blanqueo de capitales y la corrupción no es obviada por el Convenio OCDE, en cuyo Art. 7 se establece que cuando en el Ordenamiento jurídico de un Estado Parte, el cohecho de sus funcionarios públicos constituya un delito conexo al blanqueo de dinero, también habrá de serlo el cohecho de agentes públicos extranjeros.

Consciente, el Convenio OCDE, de la importancia de prevenir los comportamientos corruptos en las transacciones comerciales internacionales, recoge una serie de medidas de carácter preventivo relacionadas con la contabilidad empresarial que los Estados Parte deberán adoptar, como la prohibición de cuentas fuera de libros, de transacciones extracontables o de partidas del pasivo con una incorrecta identificación de su objeto, con el fin de corromper a agentes públicos de otros Estados o de ocultar tal corrupción (Art. 8.1).

La cooperación judicial y policial se configura como un pilar elemental en la lucha contra delitos, como el que aquí nos ocupa, con un evidente carácter internacional. Por ello, el Convenio exige a las Partes que se proporcionen una asistencia jurídica pronta y eficaz, y no sólo en las investigaciones y procedimientos penales, sino también en actuaciones no penales dirigidas contra personas jurídicas (Art. 9.1). Si un Estado Parte hace depender la prestación de asistencia mutua de la existencia de doble tipificación de un delito, se considerará que ésta existe si el delito respecto del cual se solicita está incluido en el Convenio OCDE. Como ya se previera en la Convención Interamericana contra la Corrupción, no podrá invocarse el secreto bancario para negar la asistencia mutua a otro Estado Parte (Art. 9.3).

Al seguir con la cooperación internacional, el Art. 10 del Convenio recoge una serie de normas sobre extradición, debe considerarse la corrupción de agentes públicos extranjeros un delito extraditable según los Ordenamientos jurídicos de los Estados Parte y los tratados de extradición entre ellas (Art. 10.1). Cuando un Estado condicione la extradición a la existencia de un tratado, y recibe una solicitud de otro Estado con el que no tiene suscrito tratado alguno, podrá considerar el Convenio como base jurídica para la extradición (Art. 10.2). En aras de evitar la impunidad, los Estados que denieguen la extradición de una persona por el delito de corrupción de agente público extranjero basándose únicamente en el hecho de que sea un nacional suyo, deberán someter el caso a las autoridades competentes para perseguir el delito (Art. 10.3).

Elemento novedoso en un documento supranacional sobre la corrupción fue la incorporación en el Art. 12 del Convenio de un mecanismo de monitoreo sobre la implementación y aplicación del mismo en los Estados Parte. El mecanismo, que parte de lo establecido en la Recomendación Revisada de 1997, se basa en un sistema de autoevaluación, configurado por las respuestas que los Estados Parte otorguen 
a un cuestionario y de evaluación mutua examinado por el Grupo de Trabajo sobre Corrupción basado en la técnica denominada "presión paritaria" entre los Estados $(\text { Comentario } 34)^{18}$.

La importancia del Convenio OCDE radica en ser el primero a nivel internacional que exige a los Estados firmantes la tipificación del cohecho activo de funcionarios públicos extranjeros e internacionales sin condicionamientos basados en posibles contradicciones con la Constitución o principios generales de los ordenamientos internos de los países participantes. Tanto es así, que el texto del Convenio ni siquiera prevé, acertadamente, la posibilidad de introducir reservas al respecto. De manera igualmente positiva ha de valorarse la inclusión del mecanismo de seguimiento previamente comentado que denota mayor interés por los Estados firmantes en el cumplimiento de las obligaciones por el Convenio impuestas.

\section{INICIATIVAS PROCEDENTES DEL CONSEJO DE EUROPA}

Fue en la $19^{\text {a }}$ Conferencia de Ministros de Justicia de los Estados miembros del Consejo de Europa, celebrada en La Valletta (Malta) en 1994, donde esta organización manifestó su deseo de luchar contra la corrupción por considerarla una seria amenaza para la democracia, el Estado de Derecho y los Derechos Humanos. Para ello, en dicha Conferencia se acordó la creación de un Grupo Multidisciplinar sobre la Corrupción (GMC), encargado de examinar medidas para incluir en un futuro programa de acción contra la corrupción y de examinar la posibilidad de elaborar una convención internacional sobre la materia que debería incluir mecanismos de seguimiento sobre su implementación ${ }^{19}$. El Programa de Acción contra la Corrupción fue adoptado por el Comité de Ministros a finales de 1996 y en él se incluía la elaboración de un convenio contra la corrupción ${ }^{20}$. Así, el 27 de enero de 1999 veía la luz la Convención Penal sobre la Corrupción, y el 4 de noviembre de ese mismo año, la Convención Civil sobre la Corrupción.

La Convención Penal contiene la definición más amplia de corrupción establecida en un tratado internacional, abarca tanto la corrupción pública como la privada, la corrupción de funcionarios públicos extranjeros pasiva y activa, y ello, sin exigir que se desarrolle en el transcurso de una operación comercial; e incluso otros comportamientos que no serían corrupción en sentido estricto como el tráfico de influencias o infracciones de carácter contable.

18 Sacerdoti, G. “Sobornar o no sobornar?, Op. cit., pp. 54-55. Los informes de supervisión tanto de la Fase 1 como de la Fase 2 pueden consultarse por países en la página Web de la OCDE: http:// www.oecd.org/document/24/0,3343,en_2649_37447_1933144_1_1_1_37447,00.html

19 Lezertua, M. "Council of Europe: an overview of Anti-Corruption Activities from 1994 to 1998", en Pieth, Mark y Eigen, Peter (Hrsg): Korruption im internationalen Geschäftsverkehr..., op. cit., pp. 228-229.

20 Cerezo, A. “La adaptación...”, Op. cit., p. 455. 
Concretamente, la Convención insta a los Estados Parte a tipificar como delito el soborno activo y pasivo de funcionarios públicos nacionales (Art. 2 y 3), el soborno activo y pasivo de miembros de asambleas nacionales (Art. 4), el soborno activo y pasivo de funcionarios públicos extranjeros (Art.5), el soborno activo y pasivo de miembros de asambleas extranjeras (Art. 6), el soborno activo y pasivo en el sector privado (Art. 7 y 8), el soborno activo y pasivo de funcionarios de organizaciones internacionales (Art.9), el soborno activo y pasivo de miembros de asambleas parlamentarias internacionales o supranacionales (Art. 10), el soborno activo y pasivo de jueces y funcionarios de tribunales internacionales (Art.11), el tráfico de influencias (Art. 12), y el blanqueo de dinero proveniente de los delitos enumerados en los Art. 2 a 12 (Art. 13). A su vez, los Estados parte deberán establecer sanciones penales o de otra índole sobre determinadas infracciones de carácter contable dirigidas a la realización de alguno de los delitos descritos en los Art. 2 a 12 (Art. 14). La Convención también insta a los Estados Parte a criminalizar los actos de participación en los delitos tipificados de acuerdo con la Convención (Art. 15). El Protocolo Adicional a la Convención Penal, de 15 de mayo de 2003, extiende la definición de corrupción al soborno activo y pasivo de árbitros y jurados nacionales y extranjeros.

La Convención aborda el tema de la responsabilidad de las personas jurídicas, insta a los Estados Parte a adoptar medidas para asegurar la responsabilidad de estos entes cuando realicen actos de corrupción, tráfico de influencias o blanqueo de dinero (Art. 18). Las sanciones deberán ser eficaces, proporcionadas y disuasorias, de naturaleza penal o de otra índole, y se incluirán sanciones monetarias.

El Art. 24 de la Convención encarga al Grupo de Estados contra la Corrupción $(\mathrm{GRECO})^{21}$ el seguimiento de la implementación de la misma por los Estados Parte. La Resolución (98) 7 de 5 de mayo de $1998^{22}$ autorizó la creación de este Grupo, a partir de las 20 directrices fundamentales en la lucha contra la corrupción ${ }^{23}$, Grupo que quedaría constituido un año después ${ }^{24}$. El objetivo del GRECO es mejorar la capacidad de sus Estados miembros en la lucha contra la corrupción a través de un mecanismo de seguimiento basado en la mutual evaluation y en la peer preasure ${ }^{25}$. Este proceso de evaluación comienza con un cuestionario que se envía a los Estados miembros para que sea completado. Posteriormente, un equipo de expertos examina

21 Consultar información sobre el GRECO en http://www.coe.int/t/dg1/Greco/Default_en.asp.

22 Resolution (98) 7 authorising the partial and enlarged Agreement establishing the "Group of States against Corruption - GRECO”, adoptada por el Comité de Ministros del Consejo de Europa el 5 mayo de 1998.

23 Resolution (97) 24 on the twenty guiding principles for the fight against corruption, adoptada por Comité de Ministros del Consejo de Europa el 6 de noviembre de 1997.

24 Resolution (99) 5 establishing the "Group of States against Corruption - GRECO", adoptada por el Comité de Ministros del Consejo de Europa el 1 de mayo de 1999.

25 Art. 1 del Estatuto del GRECO, recogido en el apéndice a la Resolución (99) 5. 
las respuestas y puede pedir, si lo considera apropiado, información adicional sobre el país en cuestión. Con la documentación obtenida, el equipo redacta un informe que debe ser discutido y adoptado por el GRECO ${ }^{26}$.

Como es tónica habitual en los instrumentos supranacionales contra la corrupción, se prevé un capítulo, el IV, relativo a la cooperación internacional, recogiéndose en él medidas referentes a la asistencia mutua y a la extradición.

A diferencia de lo que ocurría con el Convenio OCDE, sí se les permite aquí a los Estados Parte formular reservas (Art. 37). No así en la Convención Civil como establece su Art. 17.

La Convención Civil sobre la Corrupción se ocupa de las víctimas de los actos de corrupción. La idea que subyace aquí es que si un funcionario público se ha visto implicado en un acto de corrupción, el Estado al cual pertenece no puede quedarse al margen y debe apoyar y reparar a las víctimas de esos hechos ${ }^{27}$. Así, el Art. 1 del mencionado texto insta a los Estados miembros a adoptar medidas para permitir a las personas que han sufrido las consecuencias de la corrupción defender sus derechos e intereses, incluida la posibilidad de obtener una compensación por el daño padecido.

El monitoreo de la implementación de la Convención Civil también se otorga al GRECO (Art. 14).

\section{INICIATIVAS PROCEDENTES DE LA UNIÓN EUROPEA}

Las primeras iniciativas europeas contra la corrupción aparecieron ligadas a la protección de los intereses financieros de la Unión. Así, ya en la Resolución del Consejo sobre la protección jurídica de los intereses financieros de las Comunidades ${ }^{28}$ se señalaba que los "los Estados miembros deberían adoptar medidas eficaces para sancionar el soborno en el que estén implicados funcionarios de las Comunidades Europeas en relación con los intereses financieros de las Comunidades" (punto 7, literal h). Posteriormente, la Resolución del Parlamento Europeo sobre la lucha contra la corrupción en Europa de 15 de diciembre de $1995^{29}$ recomendaba combatir la corrupción "tanto en relación con la protección de los intereses financieros de la UE como a nivel más amplio". Sin embargo, seguiría siendo en ese ámbito donde se continuasen dando pasos en la lucha contra la corrupción.

26 Lezertua, M. “Council of Europe...”, Op. cit., p. 234. Los informes de la primera y de la segunda ronda pueden consultarse por países en la siguiente dirección de Internet: http://www.coe.int/t/dg1/ greco/documents/index_en.asp.

27 De La Cuesta ArzamendI, J. "Iniciativas internacionales contra la corrupción” en: De La Cuesta Arzamendi, J., y otros: Justicia social y Derechos Humanos en la era de la globalización y la multiculturalidad, LXVI Curso Internacional de Criminología, Cuaderno del Instituto Vasco de Criminología, San Sebastián, Nº 12- 2003, p. 15.

28 DOCE $n^{\circ}$ C 355, de 14 de diciembre de 1994.

29 DOCE $\mathrm{n}^{\circ} \mathrm{C}$ 017, de 22 de enero de 1996 
Así, es en el Primer Protocolo Adicional ${ }^{30}$ al Convenio relativo a la protección de los intereses financieros de las Comunidades Europeas ${ }^{31}$ (en adelante, Convenio PIF) donde se establecen las primeras obligaciones para los Estados miembros en materia de corrupción de funcionarios públicos tanto nacionales como comunitarios. Dicho documento, considera que "los intereses financieros de las Comunidades Europeas pueden verse afectados o amenazados por otras infracciones penales, en especial, las constituidas por actos de corrupción cometidos por o respecto de funcionarios nacionales o comunitarios responsables de la percepción, la gestión o el desembolso de los fondos comunitarios sometidos a su control", obliga a los Estados miembros a castigar penalmente, con sanciones eficaces, proporcionadas y disuasorias (Art. 5), los actos de corrupción pasiva y activa de funcionarios públicos nacionales y comunitarios cuando "causen o puedan causar perjuicio a los intereses financieros de las Comunidades Europeas" (Art. 2 y 3).

La necesidad de otorgar un tratamiento más amplio al problema de la corrupción ${ }^{32}$ motivó la adopción por parte Consejo de la Unión Europea del Convenio relativo a la lucha contra los actos de corrupción en los que estén implicados funcionarios de las Comunidades Europeas o de los Estados miembros de la Unión Europea ${ }^{33}$. Inspirado en el Primer Protocolo, el Convenio tiene un ámbito de aplicación mayor, no limitándose a supuestos que lesionen los intereses financieros de la Unión ${ }^{34}$.

El Convenio (Art. 1) y el Primer Protocolo (Art. 1) utilizan idéntica definición de funcionario. Por funcionario comunitario se entenderá "toda persona que tenga la condición de funcionario o de agente contratado en el sentido del Estatuto de los funcionarios de las Comunidades Europeas o del Régimen aplicable a otros agentes de las Comunidades Europeas, toda persona puesta a disposición de las Comunidades Europeas por los Estados miembros o por cualquier organismo público o privado, que ejerza en ellas funciones equivalentes a las que ejercen los funcionarios $u$ otros agentes de las Comunidades Europeas". Además, "se asimilarán a los funcionarios

30 Protocolo establecido sobre la base del artículo K.3 del Tratado de la Unión Europea, del Convenio relativo a la protección de los intereses financieros de las Comunidades Europeas, de 27 de septiembre de 1996 (DOCE n C 313, de 23 de octubre). En vigor desde el 17 de octubre de 2002.

31 Convenio establecido sobre la base del artículo K.3 del Tratado de la Unión Europea, relativo a la protección de los intereses financieros de las Comunidades Europeas, de 26 de julio de 1995 (DOCE n ${ }^{\circ} \mathrm{C} 316$, de 27 de noviembre). En vigor desde el 17 de abril de 2003.

32 Carrera, F. "La persecución penal...", Op. cit., p. 217; Cerezo, A. "La adaptación...”, Op. cit., p. 455; Huber, Bárbara. "La lucha contra la corrupción desde una perspectiva supranacional”, Trad. de Miguel Ontiveros Alonso, en: Revista Penal, n 11/2003, p. 44.

33 Convenio establecido sobre la base de la letra c del apartado 2 del artículo K.3 del Tratado de la Unión Europea relativo a la lucha contra los actos de corrupción en los que estén implicados funcionarios de las Comunidades Europeas o de los Estados miembros de la Unión Europea, de 26 de mayo de 1997 (DOCE n ${ }^{\circ}$ C 195, de 25 de junio). En vigor desde el 28 de septiembre de 2005.

34 El preámbulo del Convenio reconoce la necesidad de superar el Protocolo y abarcar todos los actos de corrupción en los que estén implicados funcionarios de las Comunidades Europeas o de los Estados miembros. 
comunitarios los miembros de organismos creados de conformidad con los Tratados constitutivos de las Comunidades Europeas, así como el personal de dichos organismos, en la medida en que el Estatuto de los funcionarios de las Comunidades Europeas o el Régimen aplicable a otros agentes de las Comunidades Europeas no les sea aplicable". No se aporta, sin embargo, definición de funcionario nacional, remitiéndose ambos textos al Derecho nacional del Estado miembro al que pertenece el sujeto para dilucidar tal cuestión. No obstante, "cuando se trate de diligencias judiciales en las que esté implicado un funcionario de un Estado miembro incoadas por otro Estado miembro, éste sólo deberá aplicar la definición de funcionario nacional en la medida en que esa definición sea compatible con su Derecho nacional", si no es compatible, puede aplicar la suya propia ${ }^{35}$. Por otra parte, no se incluyen dentro de la noción de funcionario que recogen ambos documentos, los funcionarios de otras organizaciones internacionales ni los de otros Estados que no sean miembros de la Unión. Así mismo, el Art. 4 de ambos documentos recoge un principio de asimilación, según el cual, los Estados miembros deberán otorgar las mismas cualificaciones por los delitos cometidos por o contra miembros de la Comisión Europea, del Parlamento Europeo, del Tribunal de Justicia de la Comunidades Europeas y del Tribunal de Cuentas que las que aplican a los miembros de sus gobiernos nacionales, de sus parlamentos nacionales, de sus máximos órganos jurisdiccionales o de sus Tribunales de Cuentas.

Los actos de corrupción pasiva y activa se describen en los Art. 2 y 3 del Convenio y del Protocolo, exigiéndose que sean hechos intencionados, ya se comentan directamente o a través de terceros. La ventaja, pecuniaria o de otra naturaleza, puede ser tanto para el funcionario como para un tercero, incluidos aquí los partidos políticos. La conducta típica consistirá en cumplir o abstenerse de cumplir, de forma contraria a sus deberes oficiales, un acto propio de su función o un acto en el ejercicio de su función. Tales actos, así como la complicidad y la instigación de los mismos, deberán ser sancionados con penas eficaces, proporcionadas y disuasorias (Art. 5 del Convenio y del Protocolo) y, al menos, para los casos más graves deben establecerse penas privativas de libertad que permitan la extradición ${ }^{36}$. No se prevé el comiso del soborno ni del producto de la corrupción ${ }^{37}$.

El Convenio no aborda el tema de la responsabilidad de las personas jurídicas, pero sí dedica su Art. 6 a la responsabilidad penal de los jefes de empresa, que insta a los Estados miembros a declarar la responsabilidad penal de los mismos así como de toda persona con poderes de decisión o de control en una empresa ${ }^{38}$.

35 Cerezo, A. “La adaptación...", Op. cit., pp. 457-458.

36 Nótese que ni el Convenio OCDE (Art. 3) ni la Convención penal sobre corrupción del Consejo de Europa (Art. 19.1) limita la exigencia a los casos más graves.

37 Se recoge en el Art. 3.3 del Convenio OCDE y en el 9.3 de la Convención penal sobre corrupción del Consejo de Europa.

38 El Segundo Protocolo al Convenio PIF, que será analizado seguidamente, sí aborda el tema. 
En orden a evitar la impunidad de los actos de corrupción realizados en el ámbito de la Unión Europea, el Convenio prevé una serie de medidas sobre la cooperación en la investigación, enjuiciamiento y ejecución de sanciones entre los Estados miembros, como son la extradición, la asistencia judicial, la transmisión de las diligencias y la ejecución de las sentencias dictadas en otro Estado miembro (Art. 8 y 9).

El Convenio PIF fue completado en junio de 1997 con un Segundo Protocolo Adicional $^{39}$. En él se exige a los Estados miembros que tipifiquen el blanqueo de capitales relacionado con el fraude y la corrupción activa y pasiva (Art. 1) y, además, se abordan algunos temas que habían quedado pendientes en el Convenio de 1997. Así, en el Art. 3 se señala que los Estados miembros deberán garantizar la responsabilidad de las personas jurídicas por actos de corrupción activa cometidos en su beneficio. El siguiente artículo indica que las sanciones impuestas a estos entes, las cuales no señala que deban tener carácter penal, deberán ser proporcionadas, eficaces y disuasorias; además advierte la necesidad de incluir multas de carácter penal o administrativo, así como otras medidas que el mismo artículo enumera expresamente (exclusión del disfrute de ventajas o ayudas públicas, prohibición temporal o permanente del desempeño de actividades comerciales, vigilancia judicial, medida judicial de disolución). Por su parte, el Art. 5 establece el embargo y la confiscación de los medios y productos de la corrupción o de bienes por valor equivalente.

Los documentos comunitarios hasta ahora señalados no tuvieron en cuenta la corrupción en el sector privado, quizá porque tradicionalmente la corrupción ha aparecido vinculada al ámbito de lo público. Sin embargo, la metodología de estos comportamientos es trasladable al ámbito de las relaciones económicas entre particulares $^{40}$. La necesidad de dar un tratamiento específico a la denominada "corrupción privada" se plasma, por primera vez, en un texto vinculante supranacional en la Acción Común 98/742/JAI sobre la corrupción en el sector privado ${ }^{41}$, que instaba a los Estados miembros a adoptar sanciones penales eficaces, proporcionadas y disuasorias con respecto a los actos de corrupción privada tanto activa como pasiva, como mínimo, cuando tales conductas supongan o puedan suponer una distorsión de la competencia, al menos en el marco del mercado común, y cuando causaran o pudieran causar perjuicios económicos a terceros debido a la adjudicación o la ejecución irregular de un contrato. La Acción Común fue sustituida por la Decisión Marco 2003/568/JAI relativa a la lucha contra la corrupción en el sector

39 Segundo Protocolo establecido sobre la base del artículo K.3 del Tratado de la Unión Europea del Convenio relativo a la protección de los intereses financieros de las Comunidades Europeas, de 19 de junio de 1997 (DOCE n ${ }^{\circ}$ C 221, de 19 de julio). Aún no ha entrado en vigor.

40 Ferré, J. (2003). "Corrupción y delitos contra la Administración Pública”, en: Ferré, J., y otros: Fraude y Corrupción en la Administración Pública, Ediciones de la Universidad de Salamanca, p. 13.

41 Acción Común 98/742/JAI adoptada por el Consejo sobre la base del artículo K.3 del Tratado de la Unión Europea, sobre la corrupción en el sector privado, de 22 de diciembre de 1998 (DOCE $n^{\circ} L$ 358 de 31 de diciembre de 1998). 
privado $^{42}$, que obliga a los Estados miembros a considerar los actos de corrupción activa y pasiva en el sector privado como constitutivos de infracción penal al menos para los casos en que tales conductas impliquen o puedan implicar una distorsión de la competencia en relación con la adquisición de bienes o de servicios comerciales.

Si bien en los instrumentos comunitarios hasta ahora descritos, en especial, en el Convenio relativo a la lucha contra los actos de corrupción en los que estén implicados funcionarios de las Comunidades Europeas o de los Estados miembros de la Unión Europea de 1997, se daban pasos importantes para lograr la armonización de la legislación penal de los Estados miembros, se observan deficientes resultados en la utilización de esta técnica, como puede comprobarse en la tardanza con la que los convenios son ratificados por los Estados miembros ${ }^{43}$. Pero, además, la armonización mínima de tipos penales que se exige en el citado convenio no soluciona el problema de la diferencia de penas en los distintos ordenamientos jurídicos, pues los Estados miembros gozan de discrecionalidad para asignar a cada supuesto una pena ${ }^{44}$. Con la intención de superar estos problemas se elaboró el Corpus Juris sobre disposiciones penales para la protección de los intereses financieros de la Unión Europea, el cual se dirige a la unificación, al menos en cuestiones básicas de parte general y de parte especial del Derecho penal, de los ordenamientos jurídico-penales de los Estados miembros de la Unión ${ }^{45}$.

El Corpus Juris fue preparado por un Grupo de Expertos bajo la dirección de la profesora DELMAS-MARTY entre los años 1995 y 1996. Su primera versión se publicó en 1997 y la segunda en el $2000^{46}$. El Corpus está orientado exclusivamente a la protección de los intereses financieros de la Unión, obviándose cualquier otro

42 Decisión Marco 2003/568/JAI del Consejo, relativa a la lucha contra la corrupción en el sector privado de 22 de julio de 2003 (DOUE $n^{\circ}$ L 192/54 de 31 de julio de 2003).

43 Vervaele, John A. E.: La Unión Europea y su espacio penal europeo: los desafíos del modelo de Corpus Juris 2000”, en: Zúñiga, L.; Méndez, C., y Diego, Ma Rosario (coord.): Derecho Penal, sociedad y nuevas tecnologías, Ed. Colex, Madrid, 2001, pp. 187-207 (Traducción de ZÚÑIGA RODRÍGUEZ), p. 200. Concretamente, el Convenio de 1997 tardó ocho años en entrar en vigor. El Segundo Protocolo al Convenio PIF, que se adoptó en 1997, no ha entrado en vigor.

44 Carrera, F. "La persecución penal...", Op. cit., p. 233.

45 Carrera, F. “La persecución penal...”, Op. cit., pp. 233-234; Méndez, C. “La corrupción en el marco del Corpus Juris", en Zúñiga, L.; Méndez, C., y Diego, Ma Rosario (coord.): El derecho penal ante la globalización, Colex, Madrid, 2002, p. 110.

46 Vid. Bacigalupo, E. (coord.): Hacia un espacio judicial europeo. Corpus Iuris de disposiciones penales para la protección de los intereses financieros de la Unión Europea, Colex, Madrid, 1998; DELMAS-MARTY, Mireille y VERVAELE, John A. E.: The implementation of the Corpus Iuris en the Member States. Penal provision for the protection of European Finances, 4 vols. Intersentia, Bruselas, 2000; DELMAS-MARTY, Mireille y VERVAELE, John A. E. (editores): Un Derecho penal para Europa: Corpus Juris 2000: un modelo para la protección penal de bienes jurídicos comunitarios, Ed. Dykinson, 2004. 
delito que no atente contra aquellos ${ }^{47}$. El documento consta de dos partes. La primera (Art. 1 a 17) dedicada al Derecho penal material, con su correspondiente parte general y parte especial. La parte especial (Art. 1 a 8) se divide, a su vez, en delitos que pueden ser cometidos por cualquier persona y delitos que sólo pueden ser cometidos por funcionarios públicos, teniendo en cuenta siempre, que deben verse afectados los intereses financieros de la Unión Europea. En el Art. 5 se recoge el delito de corrupción. El texto ofrece una definición de funcionario público comunitario que coincide con la del Convenio de 1997 y, del mismo modo, se remite al Derecho interno de cada Estado miembro para conceptualizar "funcionario nacional". Define, también, corrupción activa y corrupción pasiva. La segunda parte del Corpus (Art. 18 a 35) recoge disposiciones de carácter procesal penal. En ella se prevé la creación del Ministerio Fiscal Europeo, compuesto por un Procurador General Europeo y Procuradores Europeos Delegados en cada Estado miembro (Art. 18). El último artículo del documento recoge un principio de subsidiariedad del Corpus Juris respecto de las legislaciones nacionales (Art. 35). El Corpus se completa con un apartado en el que se recogen una serie de principios tradicionales, como son los de legalidad, culpabilidad, proporcionalidad de las penas y el de garantía judicial; y lo que denomina "nuevos" principios: el de territorialidad europea y el procedimiento contradictorio.

\section{INICIATIVAS PROCEDENTES DE LA ONU. ESPECIAL REFERENCIA A LA CONVENCIÓN DE NACIONES UNIDAS CONTRA LA CORRUPCIÓN.}

\section{Los comienzos de la lucha contra la corrupción en el seno de las Naciones Unidas}

Los primeros intentos de las Naciones Unidas por acabar con las prácticas corruptas en las transacciones comerciales internacionales se remontan al año 1975, momento en que la Asamblea General aprueba la Resolución 3514 (XXX) de medidas contra las prácticas corruptas de las empresas transnacionales y de otras empresas, de sus intermediarios y de otros implicados en tales prácticas, que sería el germen de una Propuesta de Acuerdo Internacional sobre Pagos Ilícitos que nunca vería la luz ${ }^{48}$.

47 Como señala Jiménez Villarejo, también se han ignorado otros delitos que sí podrían perjudicar al erario de la Unión Europea o que podrían aparecer conexos a los recogidos en el documento, como la prevaricación, el tráfico de influencias y el uso de información privilegiada. Jiménez Villarejo, Carlos: "Transnacionalización de la delincuencia y persecución penal", en VV.AA.: Crisis del sistema politico, criminalización de la vida pública e independencia judicial, Estudios de Derecho Judicial, CGPJ, Madrid, 1998, p. 80.

48 Cockcroft, L. "Globalización de los mercados y corrupción. El marco internacional para la lucha contra la corrupción internacional”, ICE, no 741 (mayo 1995), p. 41. 
Durante los años ochenta, las tensiones Este-Oeste impedirían cualquier tipo de avance en la negociación de un texto internacional contra la corrupción ${ }^{49}$. Tras la caída del muro de Berlín y el fin de la división del mundo en dos bloques se retoman los trabajos en el seno de la Asamblea General de la ONU. Así, se adoptan, sin carácter vinculante, una serie de resoluciones ${ }^{50}$ y la Declaración de las Naciones Unidas contra la corrupción y el soborno en las transacciones comerciales internacionales $^{51}$, por la cual, los Estados miembros se comprometen a adoptar medidas efectivas y concretas para luchar contra todas las formas de corrupción, soborno y prácticas ilícitas conexas en las transacciones comerciales internacionales, a tipificar como delito los actos de soborno de funcionarios públicos extranjeros, a prohibir la deducción fiscal de las sumas pagadas como sobornos, a elaborar normas y prácticas contables que aumenten la transparencia de las transacciones comerciales internacionales, a elaborar códigos de conducta que prohíban la corrupción en las transacciones comerciales internacionales, a examinar la necesidad de tipificar como delito el enriquecimiento ilícito de funcionarios públicos, y a prestarse la mayor asistencia mutua y cooperación en la investigación de la corrupción transnacional.

También sin carácter vinculante se adopta el 15 de diciembre de 1998, la Acción contra la corrupción y el soborno en las transacciones internacionales. Poco tiempo después, en 1999, la Oficina de las Naciones Unidas sobre drogas y sobre prevención del delito publicó en Viena el Programa Global contra la Corrupción ${ }^{52}$, con objetivos similares a los del GRECO pero a nivel mundial, buscaba la aprobación de instrumentos internacionales contra la corrupción. El Programa también tiene objetivos a nivel nacional consistentes, fundamentalmente, en lograr apoyo y ayuda técnica entre los Estados para elaborar normas y mecanismos de prevención, así como para la formación de los propios funcionarios o agentes destinados a la lucha contra la corrupción ${ }^{53}$

Con la entrada del nuevo milenio, se intensifica la lucha contra la delincuencia organizada transnacional y también contra la corrupción como una de sus principales

49 Cockcroft, L. (2001). "Globalización de los mercados...” Op. cit., p. 42; STESSENS, Guy "The international fight against corruption. General Report”, en Revue Internationale de Droit Pénal, vol. 72, 3-4, p. 896.

50 Resolución de la Asamblea General 50/106, Business and development, de 20 de diciembre de 1995 (A/RES/50/106), en la que se recomendaba al Consejo Económico y Social examinar el proyecto de acuerdo internacional sobre pagos ilícitos; Resolución de la Asamblea General 51/59, Action against corruption and international Code of Conduct for Public Officials, de 12 de diciembre de 1996 (A/RES/51/59), en la que se adopta un Código de Conducta para funcionarios públicos, en el que se señala que éstos no deberán solicitar o recibir directa ni indirectamente regalos u otros beneficios que puedan influir en el ejercicio de su funciones.

51 Resolución de la Asamblea General 51/191, United Nations Declaration against Corruption and Bribery in International Commercial Transactions, de 21 de febrero de 1997 (A/RES/51/191).

52 Vid. Información acerca del mismo así como de otras iniciativas contra la corrupción derivadas de la ONU en http://www.unodc.org/unodc/en/corruption/index.html.

53 De La Cuesta Arzamendi, J. "Iniciativas internacionales...”, Op. cit., p. 21; HUBER, Bárbara: "La lucha contra la corrupción...”, p. 46. 
manifestaciones. El 15 de noviembre del año 2000 se adopta en Palermo la Convención de Naciones Unidas contra el Crimen Organizado Transnacional ${ }^{54}$, en cuyo Art. 8 se insta a los Estados miembros a criminalizar el cohecho activo y pasivo, ya sea de funcionarios nacionales o extranjeros. Poco tiempo después, la Asamblea General de la ONU aprueba la Resolución $55 / 61^{55}$, en la que la Organización reconoce la conveniencia de elaborar un instrumento jurídico internacional eficaz contra la corrupción, independiente de la Convención de Palermo, y decide establecer un comité especial encargado de la negociación de dicho instrumento. Días después se aprueba la Resolución $55 / 188^{56}$, en la que reitera la necesidad de adoptar medidas nacionales e internacionales para combatir la corrupción en las transacciones comerciales internacionales y resalta la importancia de elaborar instrumentos contra la transferencia ilícita de fondos y la necesidad de restituir esos fondos a sus países de origen. Así mismo, reitera la petición al Secretario General ya contenida en la Resolución 55/61 sobre la constitución de un grupo intergubernamental de expertos encargado de preparar la negociación de un futuro instrumento jurídico contra la corrupción, a la vez que invita al grupo de expertos a examinar la cuestión de los fondos transferidos ilícitamente y la repatriación de esos fondos a sus países de origen. El resultado de las negociaciones fue la Convención de Naciones Unidas contra la Corrupción, adoptada en Mérida (México) el 31 de octubre de $2003^{57}$.

La importancia de este documento radica en ser el primer instrumento contra la corrupción de carácter vinculante y global, frente a las iniciativas regionales habidas hasta el momento ${ }^{58}$. Por otra parte, incluye elementos innovadores, como el delito de obstrucción de la justicia, y presta una muy especial atención a la recuperación de activos.

\section{La Convención de Naciones Unidas contra la Corrupción}

La Convención consta de un preámbulo y ocho capítulos. El primero recoge los objetivos de la Convención y algunas definiciones, entre ellas, la de funcionario público, funcionario público extranjero $\mathrm{y}$ funcionario de una organización

54 En vigor desde el 29 de septiembre de 2003.

55 Resolución de la Asamblea General 55/61, un instrumento jurídico internacional eficaz contra la corrupción, de 4 de diciembre de 2000 (A/RES/55/61).

56 Resolución de la Asamblea General 55/188, Prevención de las prácticas corruptas y la transferencia ilícita de fondos y luch a contra ellas y repatriación de esos fondos a sus países de origen, de 20 de diciembre de 2000 (A/RES/55/61).

57 Entró en vigor el 14 de diciembre de 2005.

58 Es necesario resaltar que, pese a los instrumentos ya existentes procedentes de organizaciones regionales (OEA, OCDE, Consejo de Europa y Unión Europea), Estados tan poderosos en el comercio internacional como China o Rusia no pertenecían a ninguna de ellas y no estaban, por tanto, obligados por ningún instrumento supranacional en materia de corrupción. 
internacional pública ${ }^{59}$. Las medidas preventivas se sitúan en el Capítulo II mientras que las conductas penalizables aparecen en el tercero. El Capítulo IV versa sobre la cooperación internacional. Las cuestiones sobre recuperación de activos se recogen en el Capítulo V. Las medidas sobre asistencia técnica e intercambio de información en el sexto. El Capítulo VII describe los mecanismos de aplicación de la convención y el último recoge una serie de disposiciones finales típicas en este tipo de documentos supranacionales.

Al comenzar con el Capítulo II, las medidas que en él se recogen están destinadas a la prevención de la corrupción tanto en el sector público como en el sector privado. Entre las primeras pueden señalarse la adopción de sistemas de transparencia y eficiencia en el acceso a la función pública (Art. 7.1), la elaboración de códigos de conducta para el correcto desempeño de las funciones públicas (Art. 8.2), el establecimiento de sistemas apropiados de contratación pública basados en la transparencia, la competencia y criterios objetivos de adopción de decisiones (Art. 9.1); el establecimiento de medidas que promuevan la obligación de rendir cuentas por la gestión en la hacienda pública (Art. 9.2); la adopción de medidas, como códigos de conducta, que refuercen la integridad y eviten toda oportunidad de corrupción entre los miembros del Poder Judicial y del Ministerio Público (Art. 11).

Para prevenir la corrupción en el sector privado, el Art. 12 de la Convención insta a los Estados parte a adoptar determinadas medidas como códigos de conducta, mecanismos para la identificación de personas jurídicas y naturales involucradas en el establecimiento y la gestión de empresas, la imposición de restricciones apropiadas y por tiempo razonable a las actividades profesionales de ex funcionarios públicos o a la contratación de funcionarios públicos en el sector privado tras su renuncia o jubilación cuando esas actividades o esa contratación estén directamente relacionadas con las funciones desempeñadas o supervisadas por esos funcionarios públicos durante su permanencia en el cargo, entre otros. El párrafo cuarto del precepto obliga a las Partes a denegar la deducción tributaria respecto de los gastos que constituyan soborno y de otros gastos que hayan tenido por objeto promover comportamientos corruptos.

Los Estados Parte, por otra parte, deberán promover la participación de la sociedad civil y de las organizaciones no gubernamentales en la prevención y lucha contra la corrupción (Art. 13), para lo cual, deberán aumentar la transparencia y promover la contribución de la ciudadanía a los procesos de adopción de decisiones, garantizar el acceso eficaz del público a la información, realizar actividades de información

59 El comité ad hoc decidió en su primera sesión no incluir una definición específica de corrupción, sino definir los concretos actos de corrupción constitutivos de delito. Vid. VV.AA. "Global Dynamics of Corruption, the Role of the United Nations Helping Member States Build Integrity to Curb Corruption", en Global programme against corruption conferences, United Nations Office for Drug Control and Crime Prevention, Centre for International Crime Prevention, Viena, octubre 2002, p.16 
pública y respetar, promover y proteger la libertad de buscar, recibir, publicar y difundir información relativa a la corrupción.

Conscientes las Partes de la vinculación existente entre la corrupción y el blanqueo de dinero, el Art. 14 de la Convención insta a las Partes a establecer un régimen interno de reglamentación y supervisión de bancos, instituciones financieras no bancarias y otros órganos susceptibles de ser utilizados para el blanqueo.

Las medidas represivas se recogen en el Capítulo III de la Convención. El instrumento de la ONU es, en este punto, más amplio que los elaborados con anterioridad por otras instancias supranacionales, insta a la tipificación de conductas que habían sido obviadas en anteriores documentos sobre corrupción. Las previsiones que se contemplan en este capítulo no tienen todas la misma fuerza obligatoria para los Estados miembros. Así, en un lado se sitúan los preceptos que tienen carácter imperativo y que conllevan la obligación de tipificar incondicionalmente como delito el cohecho activo y pasivo de funcionarios públicos nacionales (Art. 15), el cohecho activo de funcionarios públicos extranjeros (Art. 16.1), la malversación o peculado, la apropiación indebida u otras formas de desviación por un funcionario público (Art. 17); el blanqueo del producto del delito (Art. 23) y la obstrucción de la justicia (Art. 25). A su vez, es obligatorio para los Estados Parte criminalizar cualquier forma de participación en un delito tipificado con arreglo a la convención así como la tentativa (Art. 27.1 y 27.2).

En otro lado se sitúan los preceptos con menos fuerza obligatoria, según los cuales, los Estados parte "considerarán la posibilidad de tipificar como delito" el cohecho pasivo de funcionarios públicos extranjeros (Art. 16.2), el tráfico de influencias (Art. 18), el abuso de funciones o del cargo (Art. 19), el enriquecimiento ilícito siempre y cuando no sea contrario a la Constitución o a los principios fundamentales del Estado en cuestión (Art. 20), la corrupción en el sector privado (Art. 21), la malversación o peculado en el sector privado (Art. 22) y el encubrimiento o la retención continua de bienes procedentes de los delitos tipificados con arreglo a la Convención (Art. 24). Como puede observarse, la Convención de Naciones Unidas contra la Corrupción recoge un amplio elenco de figuras delictivas, algunas de ellas totalmente novedosas en instrumentos internacionales en la lucha contra la corrupción como la figura, de obligada criminalización por parte de los Estados Parte, de la obstrucción de la justicia.

La Convención también aborda el tema de la responsabilidad de las personas jurídicas (Art. 26), deben adoptar los Estados Parte las medidas necesarias para establecer la responsabilidad penal, civil o administrativa de las personas jurídicas por su participación en delitos tipificados de acuerdo a la Convención, siempre de acuerdo con los principios jurídicos de sus ordenamientos internos. Las sanciones impuestas a tales entidades, ya sean penales o no penales, habrán de ser eficaces, proporcionadas y disuasivas, incluyéndose las sanciones monetarias.

Por otra parte, la Convención insta a los Estados parte a establecer el comiso del producto del delito o de bienes por valor equivalente, así como de los bienes, equipos 
u otros instrumentos utilizados o destinados a utilizarse en la comisión de los delitos tipificados con arreglo a la Convención (Art. 31).

También se recogen en este Capítulo una serie de medidas procesales tendentes a proteger a testigos, peritos y víctimas (Art. 32), así como a los denunciantes de buena fe de los delitos que se prevén en la Convención (Art. 33).

Un elemento significativo que prevé la Convención es la obligación de los Estados Parte de garantizar a las entidades y personas perjudicadas por actos de corrupción su derecho a obtener una indemnización (Art. 35).

En el Capítulo IV se recogen medidas sobre cooperación internacional, extradición y asistencia judicial recíproca. Cuando un Estado Parte que supedita la extradición a la existencia de un tratado recibe una solicitud de extradición de otro Estado Parte con el que no le vincula ningún tratado de extradición, podrá considerar la Convención como la base jurídica de la extradición.

Dada la importancia que la Convención de Naciones Unidas contra la corrupción otorga a la recuperación de activos (su Art. 51 lo considera un "principio fundamental" de la Convención), se dedica a ese tema un Capítulo completo, el V, en el que se recogen pormenorizadamente una serie de normas sobre cooperación y asistencia en esta materia.

Con la Convención de Naciones Unidas contra la Corrupción parece culminar una etapa en la lucha mundial contra la corrupción iniciada en 1996 con la Convención Interamericana contra la Corrupción, configurándose así la Convención de Naciones Unidas como el primer instrumento obligatorio de alcance verdaderamente universal en esta materia. Son diversos los aciertos de la Convención, por ejemplo, la especial atención que presta a la prevención de la corrupción, tanto en el sector público como en el sector privado, al fomentar la participación activa de la sociedad civil y de las organizaciones no gubernamentales en la prevención y lucha contra la corrupción. Igualmente, destaca la amplitud de conductas delictivas que deben tipificarse por los Estados Parte, si bien hubiera sido deseable otorgar más fuerza obligatoria a algunos preceptos como el destinado a penalización de la corrupción pasiva de funcionarios extranjeros, como ya se exige en la Convención Penal sobre Corrupción del Consejo de Europa, del tráfico de influencias o del abuso de funciones del cargo. De manera especialmente positiva ha de valorarse el novedoso Capítulo concerniente a la recuperación de activos, más desarrollado que en cualquier otro instrumento supranacional anticorrupción, y que prevé, por ejemplo, que esos fondos se destinen a la indemnización de víctimas de los delitos tipificados de acuerdo a la Convención (Art. 57.3.c). Por el contrario, es criticable la ausencia de mecanismos de seguimiento, que trae su causa en el rechazo a los mismos por parte de algunos Estados al considerar que violaban su soberanía ${ }^{60}$. No obstante, se prevé la creación

60 Argandoña, A. (2006). "La convención de las Naciones Unidas contra la corrupción y su impacto sobre las empresas internacionales", Documento de investigación DI n ${ }^{\circ}$ 656, IESE Business School Universidad de Navarra, octubre, pp. 10-11. 
de una Conferencia de los Estados Parte, entre cuyas funciones estará la de examinar periódicamente la aplicación de la Convención por parte de los Estados Parte (Art. 63.4.c). Por último, hay que señalar que entre las disposiciones finales aparece una novedosa por ser única en los instrumentos supranacionales contra la corrupción. Así, el Art. 67.2 permite la firma de la Convención por organizaciones regionales de integración económica siempre que al menos uno de sus Estados miembros haya firmado la Convención.

\section{REFLEXIONES FINALES}

Más de treinta años han pasado desde que las primeras iniciativas de carácter supranacional para combatir la corrupción vieran la luz en el seno de la Organización para la Cooperación y el Desarrollo Económico y en la Organización de la Naciones Unidas. Sin embargo, aquellas no pasaron de meras declaraciones de intenciones sin fuerza obligatoria para los Estados Parte. Durante los años ochenta, la situación política mundial impidió avanzar en la lucha global contra la corrupción. La comunidad internacional habría de esperar hasta mediados de los noventa, década marcada por los escándalos corruptos que afectaron a diversos gobiernos de países de todo el mundo, para ver nacer textos supranacionales contra la corrupción de carácter vinculante. Las iniciativas se fraguaron en el seno de organizaciones de carácter regional -OEA, OCDE, Consejo de Europa, Unión Europea-, resistiéndose la adopción de un texto con verdadera vocación universal. Con el cambio de siglo llegaría tan ansiado documento: la Convención de Naciones Unidas contra la Corrupción del año 2003, firmada por 140 Estados de los 192 que forman parte de dicha organización.

Como se reconoce en ese mismo texto, la corrupción ha pasado a ser en nuestros días un problema que no conoce fronteras. Convertido así en un fenómeno global, requiere soluciones globales. Por ello, ante la imposibilidad de acabar con la corrupción con medidas puramente nacionales, se erige como elemento fundamental en la lucha contra este fenómeno la cooperación de todos los Estados, para dar cumplimiento a lo acordado en los diversos textos supranacionales comentados a los largo de estas páginas. Fundamental es, por tanto, que los Estados cumplan con una de las prescripciones que aparecen de manera habitual en los diversos documentos de lucha contra la corrupción, la de prestarse asistencia mutua y cooperación en la investigación de los comportamientos corruptos, así como en la persecución y enjuiciamiento de los responsables ${ }^{61}$.

Así mismo, consideramos de suma importancia la colaboración entre países no sólo para perseguir a los delincuentes, sino también para perseguir los fondos

61 Art. 13 y ss. de la Convención Interamericana contra la Corrupción; Art. 9 y 10 del Convenio de lucha contra la corrupción de agentes públicos extranjeros en las transacciones comerciales internacionales de la OCDE; Capítulo IV de la Convención Penal sobre Corrupción del Consejo de Europa; Capítulo IV de la Convención de Naciones Unidas contra la corrupción. 
sustraídos por los sujetos corruptos. Recuperar esos fondos y restituírselos a sus legítimos propietarios es la mejor manera de saldar la deuda con quienes han sufrido los maliciosos efectos de la corrupción.

Por otra parte, a nivel interno, los Estados deben cumplir estrictamente con lo indicado en las diversas convenciones internacionales, adoptar, por una parte, las medidas necesarias para prevenir los comportamientos corruptos tanto en la Administración Pública como en el sector privado, abogar en todo momento por la transparencia y elaborar códigos de conducta para los funcionarios y para las empresas. Por otra parte, tipificar como delito todos los actos de corrupción que se enumeran en las convenciones, y sancionándolos con penas eficaces, proporcionadas y disuasorias, que faciliten la asistencia mutua y la extradición.

\section{REFERENCIAS}

Argandoña, A. (2006). "La convención de las Naciones Unidas contra la corrupción y su impacto sobre las empresas internacionales", Documento de investigación DI $n^{o}$ 656, IESE Business School Universidad de Navarra, octubre.

Bacigalupo, E. (coord.) (1998). Hacia un espacio judicial europeo. Corpus Iuris de disposiciones penales para la protección de los intereses financieros de la Unión Europea, Colex, Madrid.

Brademas, J., y Heimann, F. (1998). "Contra la corrupción internacional”, en Política Exterior, Vol. XII, noviembre-diciembre, $\mathrm{n}^{\circ} 66$.

Carrera, F. (2001). “La persecución penal de la corrupción en la Unión Europea”, en VV.AA.: Cooperación jurídica internacional, BOE, Colección Escuela Diplomática. Madrid.

Cebada, A. (2002). "La participación española en las acciones internacionales contra la corrupción", en Derecho de los Negocios, año 13 N ${ }^{\circ} 144$, septiembre.

Cerezo. A. (2001). "La adaptación del sistema jurídico-penal español a las propuestas internacionales sobre corrupción administrativa", en: Actualidad Penal, $n^{\circ} 21$, XXI.

Cockcroft, L. (1995). “Globalización de los mercados y corrupción. El marco internacional para la lucha contra la corrupción internacional”, en: Información Comercial Española, n 741 (mayo 1995).

De La Cuesta Arzamendi. J. (2003) "Iniciativas internacionales contra la corrupción", en: De la Cuesta Arzamendi, J., y otros: Justicia social y Derechos Humanos en la era de la globalización y la multiculturalidad, LXVI Curso Internacional de Criminología, Cuaderno del Instituto Vasco de Criminología, san Sebastián, $N^{0} 12$.

Delmas-Marty, M., y Vervaele, J. A. E. (2002). The implementation of the Corpus Iuris on the Member States. Penal provision for the protection of European Finances, 4 vols. Intersentia, Bruselas. 
Delmas-Marty, M., y Vervaele, J. A. E. (editores) (2004). Un Derecho penal para Europa: Corpus Juris 2000: un modelo para la protección penal de bienes jurídicos comunitarios, Ed. Dykinson.

Fabián, E. (2003). La corrupción de agente público extranjero e internacional, Tirant lo Blanch, Valencia.

Huber, B. (2993). "La lucha contra la corrupción desde una perspectiva supranacional", trad. de Miguel Ontiveros Alonso, en: Revista Penal, $\mathrm{n}^{\mathrm{o}} 11$.

Jiménez, C. (1998). “Transnacionalización de la delincuencia y persecución penal", en VV.AA.: Crisis del sistema político, criminalización de la vida pública e independencia judicial, Estudios de Derecho Judicial, CGPJ, Madrid.

Lezertua, M. (1998). "Council of Europe: an overview of Anti-Corruption Activities from 1994 to 1998”, en PIETH, Mark y EIGEN, Peter (Hrsg): Korruption im internationalen Geschäftsverkehr. Bestandsaufnahmen, Bekämpfung, Prävention, Ed. Luchternahd, Frankfurt am Main.

Madrid, M. (1998). "Acciones internacionales en la lucha contra la corrupción”, Derecho de los negocios, Año n ${ }^{\circ}$ 9, $\mathrm{N}^{\circ} 91$

Manfroni, C. (1998). Soborno transnacional, Abeledo-Perrot, Buenos Aires.

Manfroni, C., y Werksman, R. (1997). La Convención Interamericana contra la corrupción. Anotada y comentada, Abeledo-Perrot, Buenos Aires.

Méndez, C. (2002). "La corrupción en el marco del Corpus Juris", en: Zúñiga Rodríguez, Laura; Méndez Rodríguez, Cristina y Diego Díaz-Santos, $\mathrm{M}^{\mathrm{a}}$ Rosario (coord.): El derecho penal ante la globalización, Colex, Madrid.

Moody-Stuart, G. (1994). La gran corrupción. Versión castellana: M. Margaret Casagualda. Siddharta Mehta Ediciones, Madrid.

Nieto, Alejandro. (1997). Corrupción en la España democrática, Ed. Ariel, Barcelona.

Nieto, Adán. (2003). "La corrupción en el comercio internacional (o de cómo la americanización del Derecho Penal puede tener de vez en cuando algún efecto positivo)", en: Revista Penal, n 12 (julio 2003).

Pieth, M. (1998). "Die Strafbarkeit der activen Bestechung ausländischer Beamter”, en: Pieth, Mark y Eigen, Peter (Hrsg): Korruption im internationalen Geschäftsverkehr. Bestandsaufnahmen, Bekämpfung, Prävention, Ed. Luchternahd, Frankfurt am Main.

Pieth, M. (2000). "International Efforts to Combat Corruption", en Alvazzi Del Frate, Anna y Pasqua, Giovanni (eds.): Responding to the Challenges of Corruption, UNICRI - ISPAC - CNPDS, Roma - Milán.

Rose-Ackerman, S. (2001). La corrupción y los gobiernos. Causas, consecuencias y reforma, Siglo Veintiuno de España Editores, Madrid, (traducción de Alfonso Colondrón Gómez).

Sacerdoti, G. (2000). “¿Sobornar o no sobornar?, en: OCDE (Ed.): Las reglas del 
juego cambiaron: La lucha contra el soborno y la corrupción, OCDE, México.

Stessens, G. (2001). "The international fight against corruption. General Report”, Revue Internationale de Droit Pénal, vol. 72, 3-4.

Tanzi, V. (2002). "Corruption around the World: causes, consequences, scope and cures", en: Abend, George T./Gupta, Sanjeev (ed.): Governance, Corruption and economic performance, International Monetary Fund, Washington D.C.

Vercher, A. (2004). "La corrupción urbanística. Una nueva expresión delictiva", en: Claves de Razón Práctica, N. 139, enero-febrero.

Vervaele, J. A. E. (2000). "La Unión Europea y su espacio penal europeo: los desafíos del modelo de Corpus Juris 2000”, en: Zúñiga Rodríguez, Laura; Méndez Rodríguez, Cristina y Diego Díaz-Santos, Ma Rosario (coord.): Derecho Penal, sociedad y nuevas tecnologías, Ed. Colex, Madrid, 2001, pp. 187-207 (Traducción de ZÚÑIGA RODRÍGUEZ).

VV.AA. (2002). "Global Dynamics of Corruption, the Role of the United Nations Helping Member States Build Integrity to Curb Corruption”, en: Global programme against corruption conferences, United Nations Office for Drug Control and Crime Prevention, Centre for International Crime Prevention, Viena, Octubre. 
